\title{
Survival after Laparoscopic Radical Surgery for Early-stage Cervical Cancer in 1316 Consecutive Cases from a National Laparoscopic Training Center in China
}

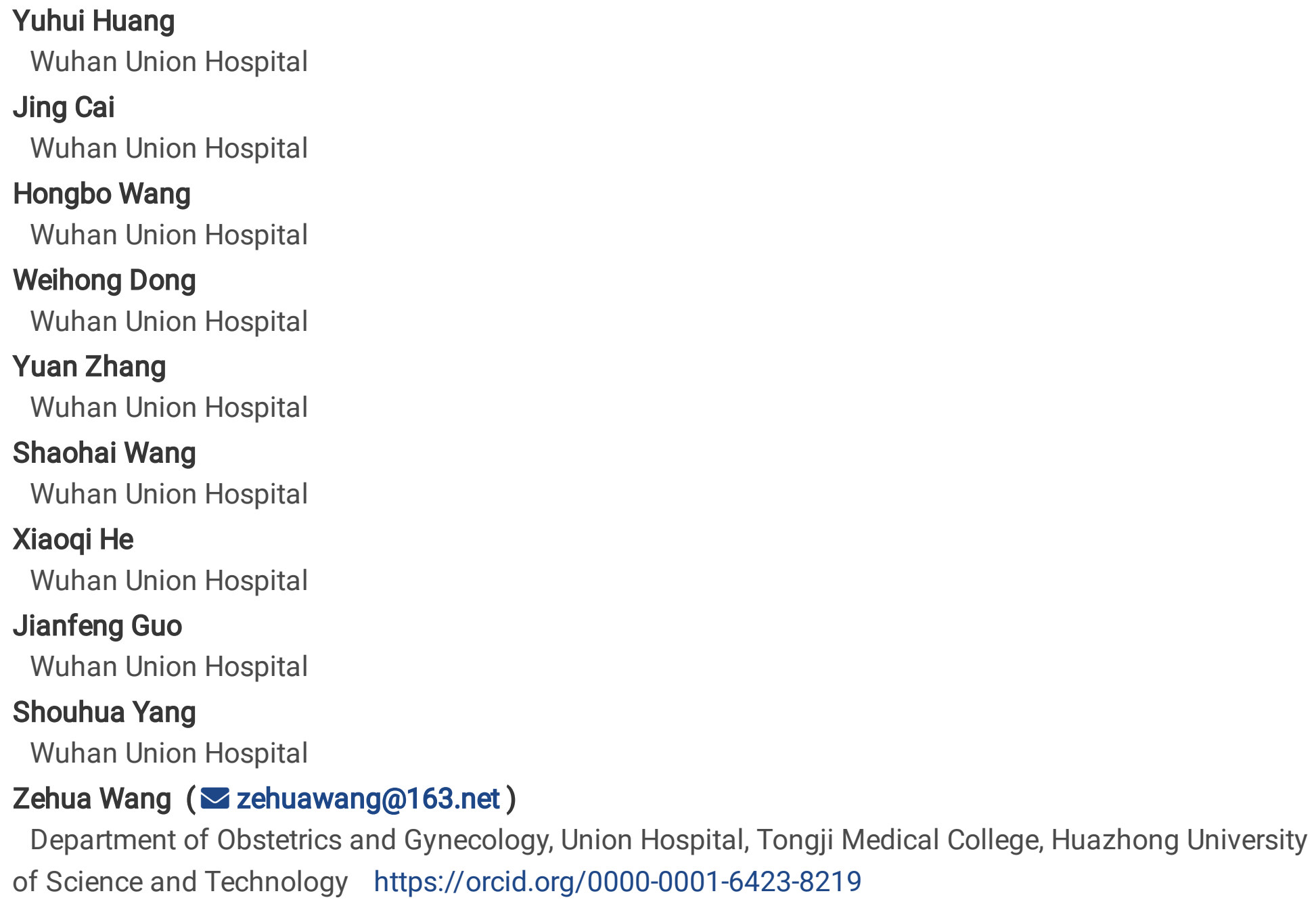

\section{Research}

Keywords: Cervical Cancer, Laparoscopy, Learning curve, Radical hysterectomy, Survival

Posted Date: September 27th, 2021

DOI: https://doi.org/10.21203/rs.3.rs-915547/v1 
License: (c) (i) This work is licensed under a Creative Commons Attribution 4.0 International License. Read Full License 


\section{Abstract}

Background: A major concern about the Laparoscopy Approach to Cervical Cancer trial is the disparities in laparoscopic radical hysterectomy experience between the participating centers and the potential effects of the learning curve of minimally invasive surgery on the oncologic outcomes of patients. Thus, it is necessary to assess the survival of cervical cancer patients undergoing laparoscopy in a minimally invasive gynecology center.

Methods: A consecutive series of patients undergoing first laparoscopic radical hysterectomy (LRH) for cervical cancer from May 2008 to December 2017 at a national laparoscopic training center were retrospectively analyzed. The overall survival (OS) and progression-free survival (PFS) were compared between groups.

Results: In total, 1316 women with FIGO (2009) stage IA-IIB cervical cancer received LRH. Among them, 1114 (84.7\%) were followed-up for 3 months or longer; the median follow-up period was 48 months (range, 3-144 months). In patients with stage IA, IB1 $(\leq 2 \mathrm{~cm})$, IB1 $(>2 \mathrm{~cm})$, IB2, IIA1 and IIA2-IIB tumors, the 4-year PFS rates were $98.6 \%, 94.5 \%, 87.4 \%, 65.6 \%, 80.0 \%$ and $67.4 \%$, respectively, and the 4 -year OS rates were $98.6 \%, 96.8 \%, 91.1 \%, 77.4 \%, 85.6 \%$ and $76.2 \%$, respectively. The 4 -year PFS and OS were as high as $96.2 \%$ and $97.5 \%$, respectively, in patients with squamous cell carcinoma of $2 \mathrm{~cm}$ or smaller in diameter. A stable high 4-year OS and PFS was achieved after completing $100 \mathrm{LRHs}$. In patients operated on by the same surgeon, an improvement in survival was observed after $40 \mathrm{LRHs}$.

Conclusion: Favorable oncologic outcomes can be achieved in patients with IA-IB1 cervical cancer after LRH in a center with a high surgery volume.

\section{Background}

Minimally invasive surgery, in comparison to laparotomy, has been associated with fewer perioperative complications and shorter postoperative convalescence periods and is widely used in the treatment of solid tumors (1-3). However, the use of laparoscopic radical hysterectomy (LRH) in the treatment of early stage cervical cancer dramatically decreased after the Laparoscopy Approach to Cervical Cancer (LACC) study data were released in 2018, which indicated a significantly increased risk for recurrence and death after minimally invasive surgery over open surgery (4). Subsequently, multiple non-randomized studies and meta-analyses comparing laparoscopy to laparotomy for cervical cancer regarding oncologic safety were published. Unfortunately, controversies exist across studies, and a consensus has not been achieved $(2,5,6)$. Therefore, it is still an open question whether minimally invasive surgery causes inferior oncologic outcomes in patients with early stage cervical cancer.

A major concern about the LACC trial is the disparities in LRH experience between the participating centers across the world and the potential effects of the learning curve of minimally invasive surgery on the oncologic outcomes of patients (7-9). Thus, it is necessary to assess the survival of cervical cancer patients undergoing laparoscopy in centers with surgeons who are highly experienced in minimally 
invasive surgery. In our center, a national training base of laparoscopic surgery techniques in China, the first-ever laparoscopic radical surgery for cervical cancer was performed in May 2008. Since then, patients with early stage cervical cancer have been preferentially subjected to LRH after careful staging and receiving informed consent. Here, we show the progression-free survival (PFS) and the overall survival (OS) of 1316 patients who received LRH at our hospital and the impacts of clinicopathological factors and learning curves on survival after minimally invasive surgery, providing evidence for deciding the appropriate surgical approach for cervical cancer and encouraging discussion in the post-LACC era.

\section{Methods}

\section{Study Design and Patients}

This study was a retrospective analysis involving a consecutive series of 1316 patients receiving LRH for cervical cancer at our center from May 2008 to December 2017. All patients with pathologically confirmed primary cervical cancer undergoing LRH were included, including those who had neoadjuvant chemotherapy before surgery because of bulky tumors, while those for whom the planned LRHs were abandoned because of intra-operatively detected inoperability were excluded. The study was approved by the Ethics Committee of the Tongji Medical College, Huazhong University of Science and Technology (No. 2020S246).

\section{Treatment Of Patients}

Before surgery, the diagnosis of cervical cancer was histologically confirmed by cervix biopsy or conization, and the spread of disease was staged by physical examination combined with imaging tests, including chest X-ray, pelvic magnetic resonance imaging (MRI) or computed tomography (CT), pelvic ultrasound and positron emission tomography (PET), as appropriate. The staging results were recorded according to FIGO 2009.

After comprehensive clinical staging, patients with IA-IB1 disease were subjected to surgery. For selected patients with locally advanced cervical cancer (FIGO IB2, IIA2, and IIB), neoadjuvant chemotherapy was applied as an alternative to radiotherapy. Paclitaxel and carboplatin were intravenously administered every 3 weeks for 2-3 cycles. After reevaluating the operability after neoadjuvant chemotherapy, patients were assigned to receive surgery or radiotherapy. The details of the chemotherapy regimen and response assessment were described in our previous report (10). A written informed consent for receiving laparoscopic surgery was obtained from all patients. The surgical procedures for LRH (Querleu-Marrow type C) and systematic bilateral pelvic lymphadenectomy, adjuvant radiotherapy, and follow-up of patients have been described previously in detail (10). The Harmonic scalpel (Ethicon Endo-Surgery, Cincinnati, Ohio) is the most frequently used energy source, and most LRHs are assisted with a uterine manipulator (Karl Storz, Germany). The vaginal cuff was closed per laparoscopy. Sentinel lymph node 
mapping or pelvic lymph node biopsy was not performed in these patients because of the limited histological examination capacity.

\section{Data Collection}

Clinical and pathological data were retrospectively retrieved. Age at diagnosis, FIGO stage, tumor size revealed by preoperative pelvic imaging tests, histological type of tumor, lymph node metastasis (LNM), lymph vascular space involvement (LVSI), parametrial involvement, surgical margin status and treatment procedures were recorded. The survival data were obtained from the medical records regarding follow-up examinations and yearly follow-up telephone interviews. OS was defined as the period of time from surgery to death from any cause or the date of the last follow-up, and PFS was defined as the period of time from surgery to disease progression or the date of the last follow-up.

\section{Statistical Analysis}

Survival curves were plotted by using the Kaplan-Meier method, and the intergroup differences in survival were evaluated by the log-rank test. To compare the survival rates in our laparoscopic cohort with those in the abdominal surgery arm of the LACC trial, the survival data of the LACC trial were extracted from the Kaplan-Meier curves by using GetData Graph Digitizer (version 2.25) and analyzed according to the method of Tierney JF, et al. (11). Univariate and multivariate Cox regression analyses were used to identify risk factors for PFS and OS. In the univariate analysis, all of the abovementioned clinicopathological parameters were included. The risk of survival was represented as a hazard ratio (HR) and its $95 \%$ confidential interval $(\mathrm{Cl})$. The significant parameters revealed by the univariate analysis were enrolled in a subsequent multivariate analysis to identify the independent risk factors. To investigate the effects of the learning curve of laparoscopy on survival in patients, the first 300 cases of LRH were divided into four groups: the 1 st 50 , the 2 nd 50 , the 2 nd 100, and the $3 \mathrm{rd} 100$, and the temporal survival trends were analyzed. All statistical analyses were performed per SPSS 26.0 (IBM Corp., Armonk, NY, USA) and visualized per GraphPad Prism 7.0 (GraphPad Software, Inc., San Diego, CA, USA). A Pvalue < 0.05 was considered statistically significant.

\section{Results}

\section{Demographic Characteristics of Patients}

Between May 2008 and December 2017, 1338 patient were subjected to receive LRH, among which 22 patients failed to complete the radical surgery and converted to radiotherapy or chemoradiation. Finally, a total of 1316 women with cervical cancer undergoing LRH were included in the present study. The median age of the patients was 46 years (range, 25-76 years). The FIGO stage ranged from IA to IIB, with IB being the most frequent stage, accounting for $67.5 \%$ of the cohort. Neoadjuvant chemotherapy was administered in $232(17.6 \%)$ patients with bulky tumors. Systematic pelvic lymphadenectomy was 
performed in all 1316 patients, and additional paraaortic lymph node dissection was performed in 21 patients. Lymph node involvement was found in $18.9 \%$ of patients. After surgery, $323(24.5 \%)$ patients underwent adjuvant radiotherapy or concomitant chemoradiation because of the presence of pathologic risk factors for recurrence. Among the 1316 patients undergoing LRH, 1114 (84.7\%) were followed-up for 3 months or longer; the median follow-up period was 48 months (range, 3-144 months). The clinicopathological characteristics in the subgroup with follow-up data did not differ from those in the entire cohort (Table 1). 
Table 1

Characteristics of all patients and patients with follow-up

\begin{tabular}{|c|c|c|c|}
\hline Characteristics & All patients & Patients with follow-up & $P$-value \\
\hline & $N=1316(\%)$ & $N=1114(\%)$ & \\
\hline Age(years) & & & 0.800 \\
\hline Median (range) & $46(25-76)$ & $46(25-76)$ & \\
\hline Mean \pm standard deviation & $46.55 \pm 8.37$ & $46.65 \pm 8.37$ & \\
\hline$<45$ & $543(41.3)$ & $454(40.8)$ & \\
\hline$\geq 45$ & 773 (58.7) & $660(59.2)$ & \\
\hline Stage (FIGO 2009) & & & 0.990 \\
\hline IA & $103(7.8)$ & $78(7.0)$ & \\
\hline $\mathrm{IB} 1(\leq 2 \mathrm{~cm})$ & $395(30.0)$ & $340(30.5)$ & \\
\hline IB1 $(>2 \mathrm{~cm})$ & $365(27.7)$ & $317(28.5)$ & \\
\hline IB2 & $126(9.6)$ & $102(9.2)$ & \\
\hline$\| \mathrm{A} 1$ & $203(15.4)$ & $171(15.4)$ & \\
\hline IIA2 & $105(8.0)$ & $89(8.0)$ & \\
\hline IIB & $19(1.4)$ & $17(1.5)$ & \\
\hline Primary tumor size & & & 0.923 \\
\hline$\leq 2.0 \mathrm{~cm}$ & $555(42.2)$ & $464(41.7)$ & \\
\hline $2.1-4.0 \mathrm{~cm}$ & $527(40.0)$ & $455(40.8)$ & \\
\hline$>4.0 \mathrm{~cm}$ & $234(17.8)$ & 195 (17.5) & \\
\hline Histology & & & 0.977 \\
\hline Squamous & $1059(80.5)$ & $902(81.0)$ & \\
\hline Adenocarcinoma & $155(11.8)$ & $131(11.8)$ & \\
\hline Adenosquamous carcinoma carcinoma & $48(3.6)$ & $38(3.4)$ & \\
\hline Others & $54(4.1)$ & $43(3.9)$ & \\
\hline Histologic grade & & & 0.986 \\
\hline G1 & $121(9.2)$ & $107(9.6)$ & \\
\hline
\end{tabular}

FIGO, International Federation of Gynecology and Obstetrics; LVSI, lymph vascular space invasion; RS: primary radical surgery; NACT, neoadjuvant chemotherapy 


\begin{tabular}{|c|c|c|c|}
\hline Characteristics & All patients & Patients with follow-up & $P$-value \\
\hline G2 & $651(49.5)$ & $552(49.6)$ & \\
\hline G3 & $378(28.7)$ & $316(28.4)$ & \\
\hline Unknown & $166(12.6)$ & $139(12.5)$ & \\
\hline Lymph node metastasis & & & 0.433 \\
\hline Negative & $1067(81.1)$ & $917(82.3)$ & \\
\hline Positive & $249(18.9)$ & $197(17.7)$ & \\
\hline LVSI & & & 0.776 \\
\hline Negative & $1027(78.0)$ & $864(77.6)$ & \\
\hline Positive & $289(22.0)$ & $250(22.4)$ & \\
\hline Parametrial involvement & & & 0.909 \\
\hline Negative & 1209 (91.9) & $1022(91.7)$ & \\
\hline Positive & $107(8.1)$ & $92(8.3)$ & \\
\hline Surgical margin & & & 0.949 \\
\hline Negative & $1280(97.3)$ & $1084(97.3)$ & \\
\hline Positive & $36(2.7)$ & $30(2.7)$ & \\
\hline Treatment & & & 0.747 \\
\hline RS & $1084(82.4)$ & 912 (81.9) & \\
\hline NACT followed by RS & $232(17.6)$ & $202(18.1)$ & \\
\hline Adjuvant radiation/chemoradiation & & & 0.665 \\
\hline No & $975(74.1)$ & $840(75.4)$ & \\
\hline Yes & $323(24.5)$ & $262(23.5)$ & \\
\hline Unknown & $18(1.4)$ & $12(1.1)$ & \\
\hline
\end{tabular}

\section{Survival After Laparoscopic Radical Hysterectomy}

The stage-weighted survival rates were analyzed. Given that 2009 FIGO stage IB1 cervical cancer is divided into stage IB1 and IB2 by the tumor size with a cut-off at $2 \mathrm{~cm}$ according to the newly issued 2018 FIGO staging criteria (12), we stratified IB1 patients accordingly. In the patients with stage IA, IB1 ( $\leq$ 
$2 \mathrm{~cm}$ ), IB1 (> $2 \mathrm{~cm})$, IB2, IIA1 and IIA2-IIB tumors, the 4-year PFS rates were 98.6\%, 94.5\%, 87.4\%, 65.6\%, $80.0 \%, 67.4 \%$, respectively, and the 4 -year OS rates were $98.6 \%, 96.8 \%, 91.1 \%, 77.4 \%, 85.6 \%, 76.2 \%$, respectively (Fig. 1A-B). These findings indicate poorer survival in patients with locally advanced disease (FIGO 2009 stage IB2, IIA2 and IIB). In contrast, the patients with 1A-IB1 tumors had excellent oncologic outcomes, with a 4-year PFS of $92.0 \%$ and a 4-year OS of $94.6 \%$, which are comparable to PFS (HR:1.31; $95 \% \mathrm{Cl}, 0.59-2.93)$ and OS (HR:1.06; $95 \% \mathrm{Cl}, 0.27-4.12)$ in the open surgery arm of the LACC study.

\section{Risk Factors For Survival}

The multivariate Cox regression analysis following the univariate analysis revealed that advanced FIGO stage (IB2-IIB), larger tumor size ( $>2 \mathrm{~cm})$, histology of non-squamous cell carcinoma, LNM, LVSI were independent risk factors for OS, and advanced FIGO stage (IB2-IIB), larger tumor size $(>2 \mathrm{~cm})$, histology of non-squamous cell carcinoma, LNM, LVSI and positive surgical margin were independent risk factors for PFS (Table 2). Given that the recommended standard care for locally advanced tumors is radiotherapy rather than surgery, we focused on patients with FIGO IA1-IB1 tumors, for whom surgery is preferred (13). In these patients, tumor size greater than $2 \mathrm{~cm}$, non-squamous cell carcinoma, LNM, and LVSI were identified as independent risk factors for OS, and tumor size greater than $2 \mathrm{~cm}$, non-squamous cell carcinoma, and LVSI were identified as independent risk factors for PFS (Table 3). The 4-year PFS and OS were as high as $96.2 \%$ and $97.5 \%$, respectively, in patients with squamous cell carcinoma of $2 \mathrm{~cm}$ or smaller in diameter. 
Table 2

Univariate and multivariate analysis of risk factors for OS and PFS in patients with stage IA-IIB (N=1114)

Variables
Univariate

$\mathrm{HR}(95 \% \mathrm{Cl})$
$1.072(0.722-$
1.593)
0.730

Age $(\geq 45$ vs. $<45$ y)

3.837 (2.567-

$5.737)$

$P$ -
value

Multivariate

HR (95\% Cl)

$P$ -

value
FIGO stage (IB2-IIB vs. IA-IB1)

Primary tumor size (> $2 \mathrm{~cm}$ vs. $\leq 2 \mathrm{~cm}$ )

Histology (others vs. squamous)

Lymph node metastasis (positive vs.

negative)

Parametrial involvement (positive vs. negative)

LVSI (positive vs. negative)

Surgical margin (positive vs. negative)

$$
\begin{aligned}
& 6.032 \text { (3.302- } \\
& 11.020)
\end{aligned}
$$

$1.981(1.304-$ $3.011)$

$4.314(2.916-$ 6.382)

$2.605(1.524-$ 4.452)

$2.516(1.683-$ $3.760)$

$1.558(0.573-$

\begin{tabular}{|c|c|c|}
\hline$<0.001$ & $\begin{array}{l}2.168(1.409- \\
3.337)\end{array}$ & $\begin{array}{l}< \\
0.001\end{array}$ \\
\hline$<.001$ & $\begin{array}{l}3.473(1.820- \\
6.625)\end{array}$ & $\begin{array}{l}< \\
0.001\end{array}$ \\
\hline 0.001 & $\begin{array}{l}2.217(1.454- \\
3.381)\end{array}$ & $<$ \\
\hline$<.001$ & $\begin{array}{l}2.520(1.643- \\
3.865)\end{array}$ & $<.001$ \\
\hline$<001$ & $\begin{array}{l}0.919(0.508- \\
1.662)\end{array}$ & 0.781 \\
\hline$<.001$ & $\begin{array}{l}1.630(1.044- \\
2.545)\end{array}$ & 0.032 \\
\hline
\end{tabular}
$4.235)$
0.385

\section{PFS}

Age $(\geq 45$ vs. $<45$ y)

FIGO stage (IB2-IIB vs. IA-IB1)

Primary tumor size ( $>2 \mathrm{~cm}$ vs. $\leq 2 \mathrm{~cm}$ )

Histology (others vs. squamous)

Lymph node metastasis (positive vs. negative)

Parametrial involvement (positive vs. negative)
$0.940(0.689-$
1.283)
0.696
3.804 (2.769- $5.225)$

4.306 (2.830$6.553)$

$1.582(1.116-$ 2.242)

3.081 (2.2334.251)

$2.493(1.612-$ $3.855)$

$<$ 0.001

0.010
$2.359(1.670-$

$<$

0.001

< $2.619(1.659-<$

$0.001 \quad 4.136)$

0.001

$1.829(1.285-$ 2.602)

0.001

$1.824(1.282-$

0.001

$0.001 \quad 2.594)$

$<\quad 0.963(0.592-$

0.881

$\mathrm{HR}$, hazard ratio; $\mathrm{Cl}$, confidence interval; FIGO, International Federation of Gynecology and Obstetrics; LVSI, lymph vascular space invasion; OS, overall survival; PFS, progression-free survival 


\begin{tabular}{|c|c|c|c|c|}
\hline \multirow[t]{2}{*}{ Variables } & \multicolumn{2}{|l|}{ Univariate } & \multicolumn{2}{|l|}{ Multivariate } \\
\hline & $\mathrm{HR}(95 \% \mathrm{Cl})$ & $\begin{array}{l}P \text { - } \\
\text { value }\end{array}$ & $\mathrm{HR}(95 \% \mathrm{Cl})$ & $\begin{array}{l}P \text { - } \\
\text { value }\end{array}$ \\
\hline LVSI (positive vs. negative) & $\begin{array}{l}2.358(1.706- \\
3.260)\end{array}$ & $<.001$ & $\begin{array}{l}1.723(1.203- \\
2.469)\end{array}$ & 0.003 \\
\hline Surgical margin (positive vs. negative) & $\begin{array}{l}2.054(1.009- \\
4.182)\end{array}$ & 0.047 & $\begin{array}{l}2.167(1.052- \\
4.465)\end{array}$ & 0.036 \\
\hline \multicolumn{5}{|c|}{$\mathrm{HR}$, hazard ratio; $\mathrm{Cl}$, confidence interval; FIGO, International Federation of Gynecology and Obstetrics; } \\
\hline \multicolumn{5}{|c|}{ LVSI, lymph vascular space invasion; OS, overall survival; PFS, progression-free surviv } \\
\hline
\end{tabular}


Table 3

Univariate and multivariate analysis of risk factors for OS and PFS in patients with IA-IB1 $(\mathrm{N}=735)$

\begin{tabular}{|c|c|c|c|c|}
\hline \multirow[t]{2}{*}{ Variables } & \multicolumn{2}{|l|}{ Univariate } & \multicolumn{2}{|l|}{ Multivariate } \\
\hline & $\mathrm{HR}(95 \% \mathrm{Cl})$ & $\begin{array}{l}P \text { - } \\
\text { value }\end{array}$ & $\mathrm{HR}(95 \% \mathrm{Cl})$ & $\begin{array}{l}P- \\
\text { value }\end{array}$ \\
\hline \multicolumn{5}{|l|}{ os } \\
\hline Age $(\geq 45$ vs. $<45 \mathrm{y})$ & $\begin{array}{l}1.672(0.855- \\
3.270)\end{array}$ & 0.133 & & \\
\hline FIGO stage (IB1 vs. IA) & $\begin{array}{l}4.902(0.672- \\
35.733)\end{array}$ & 0.117 & & \\
\hline Primary tumor size (>2cm vs. $\leq 2 \mathrm{~cm}$ ) & $\begin{array}{l}3.016(1.522- \\
5.979)\end{array}$ & 0.002 & $\begin{array}{l}2.599(1.286- \\
5.255)\end{array}$ & 0.008 \\
\hline Histology (others vs. squamous) & $\begin{array}{l}2.941(1.544- \\
5.601)\end{array}$ & 0.001 & $\begin{array}{l}3.599(1.848- \\
6.852)\end{array}$ & $\dot{0} 001$ \\
\hline $\begin{array}{l}\text { Lymph node metastasis (positive vs. } \\
\text { negative) }\end{array}$ & $\begin{array}{l}3.617(1.824- \\
7.170)\end{array}$ & $<.001$ & $\begin{array}{l}2.488(1.171- \\
5.117)\end{array}$ & 0.017 \\
\hline $\begin{array}{l}\text { Parametrial involvement (positive vs. } \\
\text { negative) }\end{array}$ & $\begin{array}{l}2.881(1.019- \\
8.147)\end{array}$ & 0.046 & $\begin{array}{l}1.183(0.381- \\
3.675)\end{array}$ & 0.771 \\
\hline LVSI (positive vs. negative) & $\begin{array}{l}2.701(1.376- \\
5.303)\end{array}$ & 0.004 & $\begin{array}{l}2.284(1.095- \\
4.766)\end{array}$ & 0.028 \\
\hline Surgical margin (positive vs. negative) & $\begin{array}{l}1.796(0.246- \\
13.093)\end{array}$ & 0.563 & & \\
\hline \multicolumn{5}{|l|}{ PFS } \\
\hline Age $(\geq 45$ vs. $<45 \mathrm{y})$ & $\begin{array}{l}1.194(0.721- \\
1.978)\end{array}$ & 0.491 & & \\
\hline FIGO stage (IB1 vs. IA) & $\begin{array}{l}8.097(1.122- \\
58.415)\end{array}$ & 0.038 & $\begin{array}{l}4.121(0.552- \\
30.788)\end{array}$ & 0.168 \\
\hline Primary tumor size (>2cm vs. $\leq 2 \mathrm{~cm}$ ) & $\begin{array}{l}2.755(1.628- \\
4.662)\end{array}$ & $\dot{0} 001$ & $\begin{array}{l}2.202(1.275- \\
3.803)\end{array}$ & 0.005 \\
\hline Histology (others vs. squamous) & $\begin{array}{l}2.246(1.335- \\
3.781)\end{array}$ & 0.002 & $\begin{array}{l}2.607(1.534- \\
4.430)\end{array}$ & $\dot{0} 001$ \\
\hline $\begin{array}{l}\text { Lymph node metastasis (positive vs. } \\
\text { negative) }\end{array}$ & $\begin{array}{l}2.523(1.411- \\
4.514)\end{array}$ & 0.002 & $\begin{array}{l}1.739(0.945- \\
3.200)\end{array}$ & 0.075 \\
\hline $\begin{array}{l}\text { Parametrial involvement (positive vs. } \\
\text { negative) }\end{array}$ & $\begin{array}{l}2.128(0.851- \\
5.322)\end{array}$ & 0.106 & & \\
\hline
\end{tabular}

$\mathrm{HR}$, hazard ratio; Cl, confidence interval; FIGO, International Federation of Gynecology and Obstetrics; LVSI, lymph vascular space invasion; OS, overall survival; PFS, progression-free survival 


\begin{tabular}{|c|c|c|c|c|}
\hline \multirow[t]{2}{*}{ Variables } & \multicolumn{2}{|l|}{ Univariate } & \multicolumn{2}{|l|}{ Multivariate } \\
\hline & $\mathrm{HR}(95 \% \mathrm{Cl})$ & $\begin{array}{l}P- \\
\text { value }\end{array}$ & $\mathrm{HR}(95 \% \mathrm{Cl})$ & $\begin{array}{l}P \text { - } \\
\text { value }\end{array}$ \\
\hline LVSI (positive vs. negative) & $\begin{array}{l}2.515(1.471- \\
4.300)\end{array}$ & 0.001 & $\begin{array}{l}2.205(1.255- \\
3.875)\end{array}$ & 0.006 \\
\hline Surgical margin (positive vs. negative) & $\begin{array}{l}1.086(0.151- \\
7.838)\end{array}$ & 0.934 & & \\
\hline \multicolumn{5}{|c|}{$\mathrm{HR}$, hazard ratio; $\mathrm{Cl}$, confidence interval; FIGO, International Federation of Gynecology and Obstetrics; } \\
\hline \multicolumn{5}{|c|}{ LVSI, lymph vascular space invasion; OS, overall survival; PFS, progression-free survival } \\
\hline
\end{tabular}

\section{Learning Curve-weighted Survival}

From 2008 to 2017, the yearly surgery volume of LRH increased from 32 to 209 cases (Fig. 2A). The first 300 cases were stratified according to the sequential order into 4 groups, i.e., the 1 st 50 cases, the 2 nd 50 cases, the $2 \mathrm{nd} 100$ cases and the 3rd 100 cases. Survival analysis revealed that the 4-year OS in the 1 st 50 cases was $84.0 \%$, which was lower than that in the 2 nd 50 cases (88.0\%), while the OS did not significantly differ between the last 2 groups (Fig. 2B). The PFS in the 1 st 50 cases was also inferior to the other 3 groups (Fig. 2C). We further analyzed the impact of the learning curve of a single surgeon on the survival of patients. The 4-year OS and PFS rates of the 1 st 40 patients were both $85.0 \%$, and improvements in OS and PFS were found after 40 cases (the $2 \mathrm{nd}-4$ th 40 versus the 1 st 40 cases, $\mathrm{HR}_{\mathrm{OS}}=$ 0.566, 95\% Cl: 0.223-1.439; $\mathrm{HR}_{\mathrm{PFS}}=0.561,95 \%$ Cl: 0.221-1.425) (Fig. 2D-E).

\section{Discussion}

Because of the high-level evidence in favor of open surgery provided by the randomized LACC trial, the use of LRH in the treatment of cervical cancer has been questioned a lot in the past 2 years (14). In the present study, we showed that the survival outcomes are acceptable in patients with early-stage cervical cancer undergoing conventional laparoscopic surgery at our center, where the mean yearly LRH volume was 131.6 cases. In addition, the learning curve is a critical factor affecting survival, suggesting that minimally invasive surgery remains an effective treatment option for patients with early-stage cervical cancer.

Generally, the survival after LRH in patients with stage IA-IB1 cervical cancer is satisfying but varies across studies, with a 5-year PFS rate ranging from $80.2-96.3 \%(5,8,15)$. In the present study, we also report a high 4-year PFS of $92.0 \%$ in patients, which is not inferior to that in the open surgery group of the LACC trial. Recently emerging evidence from non-randomized studies and meta-analyses comparing survival after minimally invasive surgery versus abdominal surgery for early-stage cervical cancer remains controversial, with some results showing compromised oncologic outcomes related to minimally invasive surgery, while others did not $(2,5,6,16-18)$. However, the application of LRH for tumors of less 
than $2 \mathrm{~cm}$ in size was supported by its non-inferior survival compared to laparotomy demonstrated by numerous studies, even by those showing increased recurrence and death risk after minimally invasive surgery (19-21). Additionally, we found that patients with $<2 \mathrm{~cm}$ squamous cell carcinoma, which can be identified preoperatively, had excellent survival outcomes after $\mathrm{LRH}$. This subpopulation would be particularly benefit from laparoscopy with fewer morbidities, shorter hospital stays, and noncompromised survival.

It is evident that surgical proficiency is a critical determinant of oncologic outcomes after surgery. We showed a poorer OS in the first 50 cases of LRH performed in our center, which was gradually improved in successive operations and reached a plateau after $100 \mathrm{LRHs}$. In patients operated on by the same surgeon, an improvement in survival was observed after $40 \mathrm{LRHs}$, suggesting that intensive practice is required to ensure the oncologic safety of surgery. Similarly, the impact of the learning curve on the oncologic outcomes of surgery for cervical cancer has been reported in two recent studies in the wake of the LACC trial $(8,9)$. Moreover, the surgery volume has been identified as an independent factor for survival. In 116 surgery centers in Japan, a high surgery volume (105 cases or more within 5 years) of LRH and systematic pelvic lymphadenectomy has been identified as a significant protective factor for PFS (HR, 0.69; 95\% Cl, 0.57-0.84) and OS ( $\mathrm{HR}, 0.75 ; 95 \% \mathrm{Cl}, 0.59-0.95)$ in cervical cancer patients, while a medium-low volume (less than 105 cases within 5 years) was not protective (22). A population-based retrospective cohort study from Canada identified 958 patients undergoing primary radical hysterectomy from 2006 to 2017 (475 minimally invasive procedures and 483 abdominal procedures) and showed increased recurrence and death in patients with stage IB cervical cancer after controlling for surgeon volume; however, the median cervical cancer volume in terms of radical hysterectomy (the number of hysterectomies performed in the 2 years prior to the indexed procedure) of 8 (range 4-12) appears generally low, being insufficient to definitively exclude the impact of surgeon volume on the survival outcomes (17). Generally, minimally invasive surgery demands more learning and practice than open surgery because of the complexity of the procedure, and the learning curve would be further prolonged in centers with low patient volume. Given the extremely imbalanced prevalence of cervical cancer around the world, with approximately $90 \%$ of newly diagnosed cases occurring in low-resource countries and few occurring in developed countries, and the significant disparities in laparoscopic proficiency and competence between counties, centers and surgeons, a global consensus on the surgical approach to cervical cancer seems difficult to achieve, and country-or center-based recommendations might be more meaningful.

The intraoperative assessment of tumor and lymph node potential risks and improvements for laparoscopic surgery for cervical cancer have been intensively discussed in the past two years. Laparoscopic vaginal dissection and cuff closure, the use of a uterine manipulator, and the $\mathrm{CO} 2$ pneumoperitoneum are considered to be processes potentially causing nosocomial dissemination of cervical cancer cells $(23,24)$. All these were used in the patients we studied. Several studies have provided retrospective evidence supporting some improvements in LRH to prevent possible tumor cell spillage. The survival after LRH with the "no-look no-touch technique" for stage IB1 tumors was found to be equal to that after open surgery (15). A multicenter analysis of 389 patients showed that LRH with 
transvaginal closure of the vaginal cuff avoided the use of a manipulator and offered oncologic outcomes similar to those of the laparotomy arm in the LACC trail (25). The use of a surgical stapler is also an option for vaginal closure to avoid tumor cell spillage (26). The potential benefits regarding oncologic safety of these adjustments need to be tested in randomized controlled trials.

Despite the relatively large number of patients involved, the limitations associated with the single-center, retrospective study design of the present study, such as selection bias and confounding bias, cannot be ignored. The missing data in the long-term follow-up of patients represents a major issue. Unfortunately, the median follow-up time was only 48 months, making an accurate estimation of the 5-year survival rate difficult. In addition, approximately $15 \%$ of patients were lost to follow-up, which might lead to some bias in the survival analysis. Further studies with long-term follow-up are needed to further clarify the oncologic outcomes after LRH in patients with early-stage cervical cancer.

\section{Conclusions}

In conclusion, favorable oncologic outcomes can be achieved in patients with IA-IB1 cervical cancer after $\mathrm{LRH}$ in a center with a high surgery volume. Surgical experience is an essential factor that needs to be considered in any future randomized trials comparing minimally invasive surgery to open surgery for cervical cancer.

\section{Abbreviations}

Laparoscopic radical hysterectomy, LRH

Overall survival, OS

Progression-free survival, PFS

the Laparoscopy Approach to Cervical Cancer, LACC

Magnetic resonance imaging, MRI

Computed tomography, CT

Positron emission tomography, PET

Lymph node metastasis, LNM

Lymph vascular space involvement, LVSI

Hazard ratio, HR

Confidential interval, $\mathrm{Cl}$ 


\section{Declarations}

\section{Ethics approval and consent to participate}

This study was approved by the Ethics Committee of the Tongji Medical College, Huazhong University of Science and Technology (No. 2020S246).

\section{Consent for publication}

Not applicable

\section{Availability of data and materials}

The data used to support the findings of this study are available from the corresponding author upon request.

\section{Competing interests}

The authors declare no conflicts of interests in this work.

\section{Funding}

This study was supported by the National Natural Science Foundation of China (81974413).

\section{Authors' contributions}

Conception \& Design of Study: JC, ZHW

Data Collection: YHH, WHD, YZ, ZHW

Data Analysis \& Interpretation :YHH, JC, SHW

Responsible Surgeon : HBW, WHD, YZ, SHW, XQH, JFG, SHY, ZHW Statistical Analysis: YHH, JC, XQH, SHY

Manuscript Preparation: YHH, JC, JFG

\section{Acknowledgements}

We thanked Dr. Si Sun for manuscript submission.

\section{References}

1. Wang W, Shang C, Huang J, Chen S, Shen H, Yao S. [Long-term oncological outcomes after laparoscopic versus abdominal radical hysterectomy in stage I a2- II a2 cervical cancer: a matched cohort study]. Zhonghua Fu Chan Ke Za Zhi. 2015;50(12):894-901.

2. Yuan Z, Cao D, Yang J, Yu M, Shen K, Yang J, et al. Laparoscopic vs. Open Abdominal Radical Hysterectomy for Cervical Cancer: A Single-Institution, Propensity Score Matching Study in China. Front Oncol. 2019;9:1107. 
3. Tantitamit T, Huang KG, Lee CL. Laparoscopic versus open radical hysterectomy in women with early stage cervical cancer: A systematic review and meta-analysis. Taiwan J Obstet Gynecol. 2020;59(4):481-8.

4. Ramirez PT, Frumovitz M, Pareja R, Lopez A, Vieira M, Ribeiro R, et al. Minimally Invasive versus Abdominal Radical Hysterectomy for Cervical Cancer. N Engl J Med. 2018;379(20):1895-904.

5. Brandt B, Sioulas V, Basaran D, Kuhn T, LaVigne K, Gardner GJ, et al. Minimally invasive surgery versus laparotomy for radical hysterectomy in the management of early-stage cervical cancer: Survival outcomes. Gynecol Oncol. 2020;156(3):591-7.

6. Nitecki R, Ramirez PT, Frumovitz M, Krause KJ, Tergas AI, Wright JD, et al. Survival After Minimally Invasive vs Open Radical Hysterectomy for Early-Stage Cervical Cancer: A Systematic Review and Meta-analysis. JAMA Oncol. 2020;6(7):1019-27.

7. Hwang JH, Yoo HJ, Joo J, Kim S, Lim MC, Song YJ, et al. Learning curve analysis of laparoscopic radical hysterectomy and lymph node dissection in early cervical cancer. Eur J Obstet Gynecol Reprod Biol. 2012;163(2):219-23.

8. Liu Y, Li L, Wu M, Ma S, Tan X, Zhong S, et al. The impact of the surgical routes and learning curve of radical hysterectomy on the survival outcomes in stage IB cervical cancer: A retrospective cohort study. Int J Surg. 2019;68:72-7.

9. Kim S, Min KJ, Lee S, Hong JH, Song JY, Lee JK, et al. Learning curve could affect oncologic outcome of minimally invasive radical hysterectomy for cervical cancer. Asian J Surg. 2021;44(1):174-80.

10. Cai J, Yang L, Dong W, Wang H, Xiong Z, Wang Z. Retrospective comparison of laparoscopic versus open radical hysterectomy after neoadjuvant chemotherapy for locally advanced cervical cancer. Int J Gynaecol Obstet. 2016;132(1):29-33.

11. Tierney JF, Stewart LA, Ghersi D, Burdett S, Sydes MR. Practical methods for incorporating summary time-to-event data into meta-analysis. Trials. 2007;8:16.

12. Bhatla N, Berek JS, Cuello Fredes M, Denny LA, Grenman S, Karunaratne K, et al. Revised FIGO staging for carcinoma of the cervix uteri. Int J Gynaecol Obstet. 2019;145(1):129-35.

13. Koh WJ, Abu-Rustum NR, Bean S, Bradley K, Campos SM, Cho KR, et al. Cervical Cancer, Version 3.2019, NCCN Clinical Practice Guidelines in Oncology. J Natl Compr Canc Netw. 2019;17(1):64-84.

14. Charo LM, Vaida F, Eskander RN, Binder P, Saenz C, McHale M, et al. Rapid dissemination of practicechanging information: A longitudinal analysis of real-world rates of minimally invasive radical hysterectomy before and after presentation of the LACC trial. Gynecol Oncol. 2020;157(2):494-9.

15. Kanno K, Andou M, Yanai S, Toeda M, Nimura R, Ichikawa F, et al. Long-term oncological outcomes of minimally invasive radical hysterectomy for early-stage cervical cancer: A retrospective, singleinstitutional study in the wake of the LACC trial. J Obstet Gynaecol Res. 2019;45(12):2425-34.

16. Gil-Moreno A, Carbonell-Socias M, Salicru S, Centeno-Mediavilla C, Franco-Camps S, Colas E, et al. Radical Hysterectomy: Efficacy and Safety in the Dawn of Minimally Invasive Techniques. J Minim Invasive Gynecol. 2019;26(3):492-500. 
17. Cusimano MC, Baxter NN, Gien LT, Moineddin R, Liu N, Dossa F, et al. Impact of surgical approach on oncologic outcomes in women undergoing radical hysterectomy for cervical cancer. Am J Obstet Gynecol. 2019;221(6):619. e1- e24.

18. Wenzel HHB, Smolders RGV, Beltman JJ, Lambrechts S, Trum HW, Yigit R, et al. Survival of patients with early-stage cervical cancer after abdominal or laparoscopic radical hysterectomy: a nationwide cohort study and literature review. Eur J Cancer. 2020;133:14-21.

19. Melamed A, Margul DJ, Chen L, Keating NL, Del Carmen MG, Yang J, et al. Survival after Minimally Invasive Radical Hysterectomy for Early-Stage Cervical Cancer. N Engl J Med. 2018;379(20):190514.

20. Kim SI, Lee M, Lee S, Suh DH, Kim HS, Kim K, et al. Impact of laparoscopic radical hysterectomy on survival outcome in patients with FIGO stage IB cervical cancer: A matching study of two institutional hospitals in Korea. Gynecol Oncol. 2019;155(1):75-82.

21. Chen $C$, Liu P, Ni Y, Tang L, Xu Y, Bin X, et al. Laparoscopic versus abdominal radical hysterectomy for stage IB1 cervical cancer patients with tumor size $</=2 \mathrm{~cm}$ : a case-matched control study. Int J Clin Oncol. 2020;25(5):937-47.

22. Matsuo K, Shimada M, Yamaguchi S, Matoda M, Nakanishi T, Kikkawa F, et al. Association of Radical Hysterectomy Surgical Volume and Survival for Early-Stage Cervical Cancer. Obstet Gynecol. 2019;133(6):1086-98.

23. Kong TW, Chang SJ, Piao X, Paek J, Lee Y, Lee EJ, et al. Patterns of recurrence and survival after abdominal versus laparoscopic/robotic radical hysterectomy in patients with early cervical cancer. $J$ Obstet Gynaecol Res. 2016;42(1):77-86.

24. Klapdor R, Hertel H, Hillemanns P, Rottger M, Soergel P, Kuehnle E, et al. Peritoneal contamination with ICG-stained cervical secretion as surrogate for potential cervical cancer tumor cell dissemination: A proof-of-principle study for laparoscopic hysterectomy. Acta Obstet Gynecol Scand. 2019;98(11):1398-403.

25. Kohler C, Hertel H, Herrmann J, Marnitz S, Mallmann P, Favero G, et al. Laparoscopic radical hysterectomy with transvaginal closure of vaginal cuff - a multicenter analysis. Int J Gynecol Cancer. 2019;29(5):845-50.

26. Boyraz G, Karalok A, Basaran D, Turan T. Vaginal Closure with EndoGIA to Prevent Tumor Spillage in Laparoscopic Radical Hysterectomy for Cervical Cancer. J Minim Invasive Gynecol. 2019;26(4):602.

\section{Figures}


A

\begin{tabular}{|c|c|c|c|c|c|c|}
\hline IA & 76 & 73 & 40 & 21 & 5 & 1 \\
\hline $\mathrm{IB} 1(\leq 2 \mathrm{~cm})$ & 340 & 288 & 144 & 71 & 17 & 1 \\
\hline $\mathrm{IB} 1(>2 \mathrm{~cm})$ & 319 & 262 & 126 & 61 & 13 & 1 \\
\hline IB2 & 102 & 62 & 27 & 12 & 3 & 1 \\
\hline IIA1 & 171 & 134 & 51 & 18 & 4 & 1 \\
\hline \|A2-IIB & 106 & 71 & 29 & 13 & 3 & 1 \\
\hline
\end{tabular}

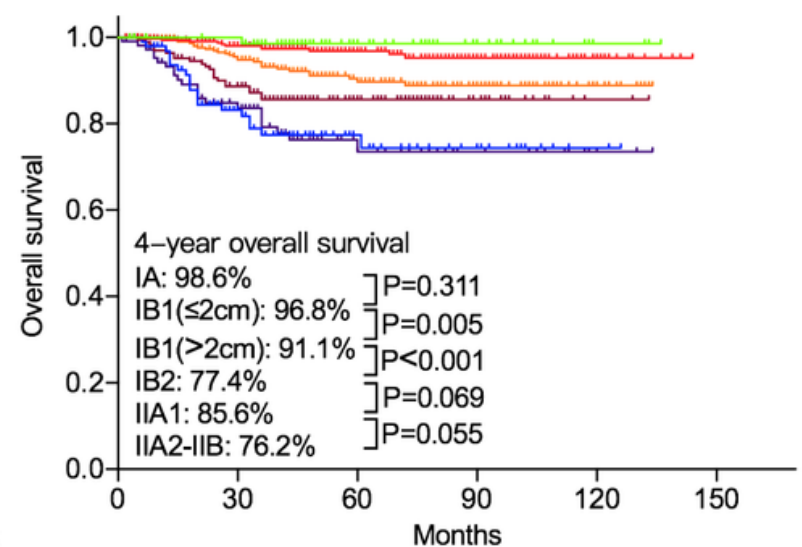

B

No. at risk

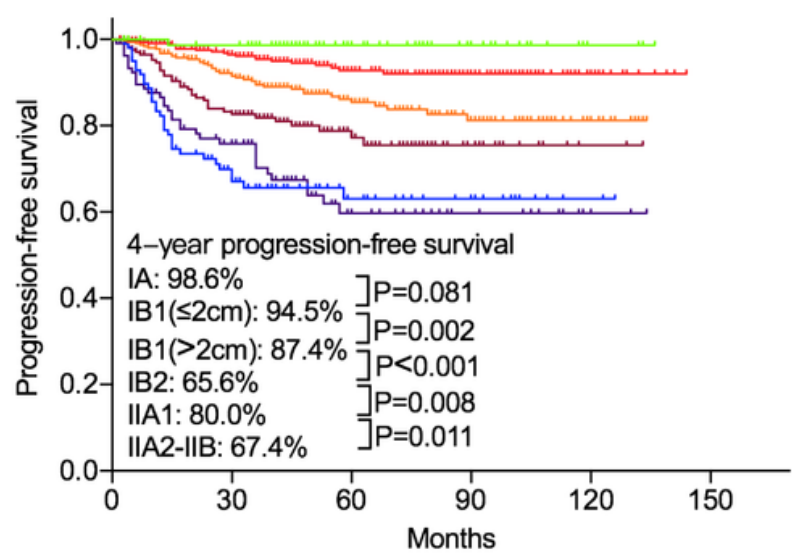

\begin{tabular}{|c|c|c|c|c|c|c|}
\hline IA & 76 & 72 & 40 & 21 & 5 & 1 \\
\hline $\mathrm{IB} 1(\leq 2 \mathrm{~cm})$ & 340 & 284 & 141 & 70 & 17 & 1 \\
\hline $\mathrm{IB} 1(>2 \mathrm{~cm})$ & 319 & 252 & 120 & 57 & 13 & 1 \\
\hline IB2 & 102 & 51 & 24 & 12 & 3 & 1 \\
\hline IIA1 & 171 & 127 & 50 & 16 & 4 & 1 \\
\hline$\|A 2-\| B$ & 106 & 63 & 27 & 13 & 3 & 1 \\
\hline
\end{tabular}

Figure 1

Survival analysis of patients with stage IA-IIB. (A) Overall survival of patient with IA-IIB (B) Progressionfree survival of patients with IA-IIB. 


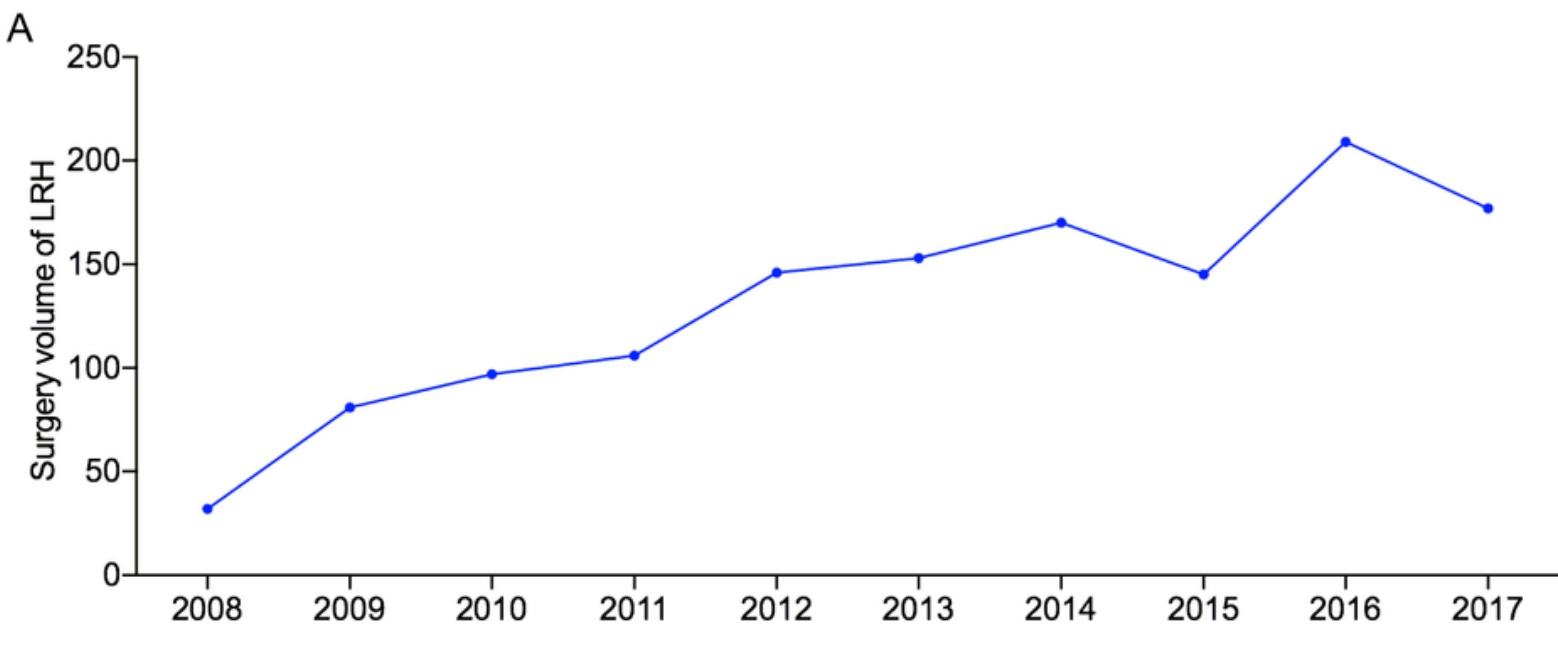

$\begin{array}{lllllllllll}\text { No. } & 32 & 81 & 97 & 106 & 146 & 153 & 170 & 145 & 209 & 177\end{array}$
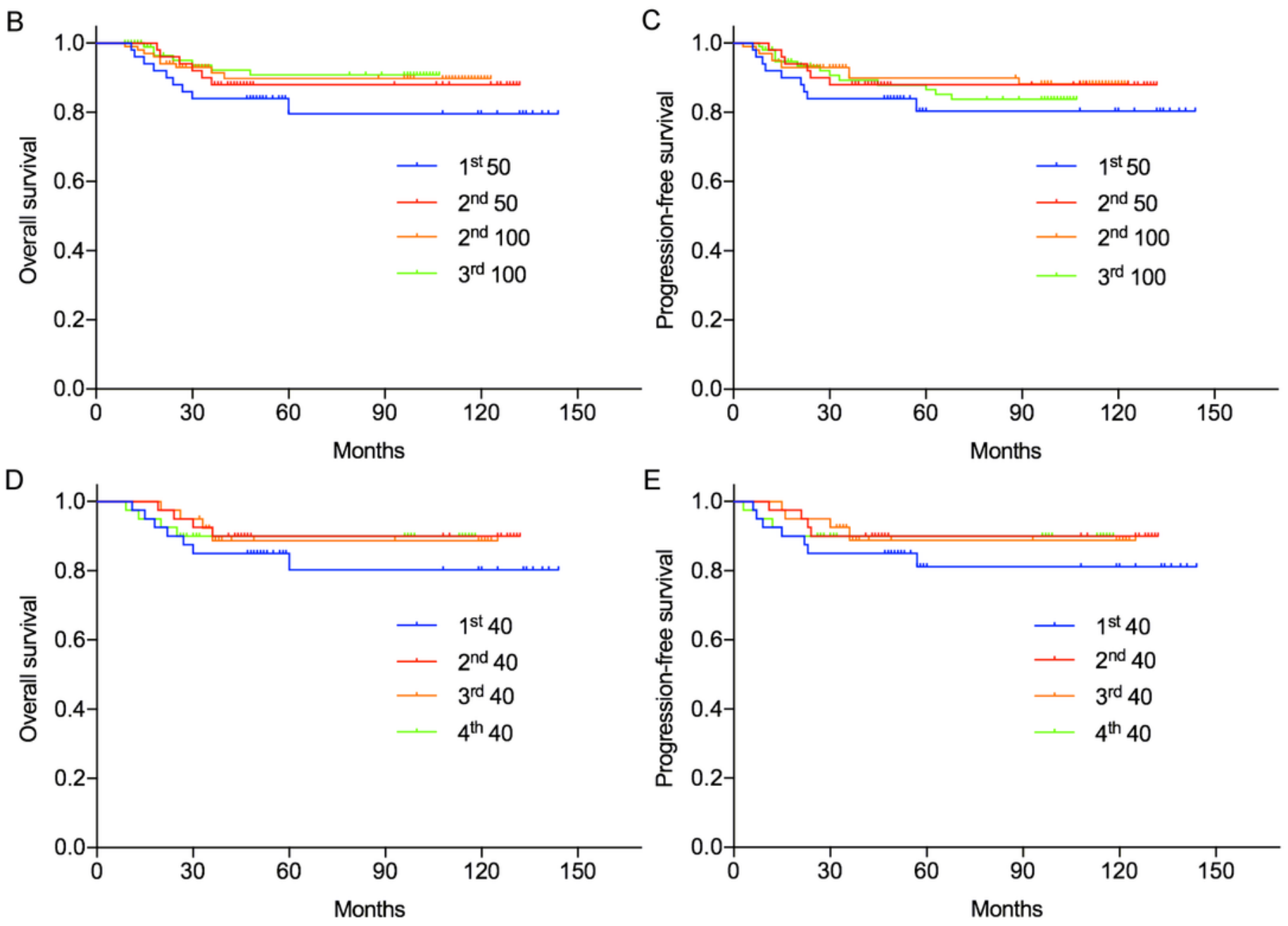

Figure 2

Learning Curve-weighted Survival. (A) Yearly surgery volume of laparoscopic radical hysterectomy, LRH; (B) Overall survival of consecutive cases in center; (C) Progression-free survival of consecutive cases in center; (D) Overall survival of consecutive cases by one surgeon; (E) Progression-free survival of consecutive cases by one surgeon. 